\title{
Esthetic and Functional Rehabilitation of Amelogenesis Imperfecta: Report of Four Cases with a One-Year Follow-Up
}

\author{
Neslihan Tekce1, Gizem Guder¹, Mustafa Demirci², Safa Tuncer², Alper Sinanoglu ${ }^{3}$, \\ Emre Ozel ${ }^{*}$ \\ ${ }^{1}$ Department of Restorative Dentistry, Faculty of Dentistry, University of Kocaeli, Kocaeli, Turkey \\ ${ }^{2}$ Department of Conservative Dentistry, Faculty of Dentistry, Istanbul University, Istanbul, Turkey \\ ${ }^{3}$ Department of Oral and Maxillofacial Radiology, Faculty of Dentistry, University of Kocaeli, Kocaeli, Turkey \\ Email: "emreozel77@gmail.com
}

Received 7 December 2015; accepted 9 April 2016; published 12 April 2016

Copyright (C) 2016 by authors and Scientific Research Publishing Inc.

This work is licensed under the Creative Commons Attribution International License (CC BY). http://creativecommons.org/licenses/by/4.0/

(c) (7) Open Access

\section{Abstract}

In this report, we describe the performance of a conservative and minimally invasive dental approach in four patients exhibiting Amelogenesis Imperfecta (AI), a structural anomaly of the enamel. In each patient, approximately $0.5 \mathrm{~mm}$ of the most external, porous, and colored enamel layer was removed, and the teeth were restored using two different nanocomposites. Posterior restorations were completed with the same approach. As a result, this contemporary restorative system is a conservative and successful treatment option to restore the loss of oral esthetics and function due to AI. Rehabilitation with direct resin restorations is not only an inexpensive treatment choice, but also a more conservative technique that reduces the amount of preparation required for teeth that are already compromised.

\section{Keywords}

Amelogenesis Imperfecta, Nanohybrid Composite, Nanofill Composite, Universal Dentin Bonding Agents

\section{Introduction}

Amelogenesis Imperfecta (AI) is a rare genetic defect in enamel mineralization. AI is characterized by heterogeneity in clinical symptoms, histological appearance, and genetic inheritance. AI occurs in 1 in 14,000 to

\footnotetext{
*Corresponding author.
}

How to cite this paper: Tekce, N., Guder, G., Demirci, M., Tuncer, S., Sinanoglu, A. and Ozel, E. (2016) Esthetic and Functional Rehabilitation of Amelogenesis Imperfecta: Report of Four Cases with a One-Year Follow-Up. Open Journal of Stomatology, 6, 103-113. http://dx.doi.org/10.4236/ojst.2016.64013 
16,000 cases, and presents a variety of clinical forms depending on the population surveyed [1] [2]. Common features of AI include quantitative and qualitative enamel deficiency, impacted teeth and abnormalities in tooth eruption, congenital absence of teeth, anterior open-bite [3], pulpal calcifications, root and coronal resorption, hypercementosis, root malformation, and taurodontism [4]-[6].

There are four main types of AI: hypoplastic (deficient formation of the matrix), hypocalcified (deficient mineralization of the formed matrix), hypomaturation (the enamel crystals remain immature), or hypomaturationhypoplastic with taurodontism (Table 1) [1] [7]-[9]. These four types of AI can be further divided into 14 subtypes. While there is little information concerning the genotype and the phenotype of AI, autosomal dominant and recessive inheritance has been reported [4]. The only known molecular defects that correlate with the incidence of AI are those of the AMELX, which encodes the protein amelogenin [10].

The major enamel matrix proteins that are known to contribute to the formation of tooth enamel are amelogenin, enamelin, and ameloblastin [11]. During secretory stages of enamel formation, these proteins are secreted by ameloblasts and play key roles in the growth of enamel crystal [7]. Hypoplastic AI results from defects in the secretory process that leads to thin or pitted enamel. The enamel in cases of hypoplastic AI can be normal or altered in structure and/or composition.

AI has a significant impact on the psychosocial health of the affected person, especially in young individuals. Because its cause is genetic, preventive treatment is not available, and treatment is focused on esthetic and functional rehabilitation [12]. Treatment depends on the severity of the case and the need for esthetic enhancement, which ranges from simple microabrasion or composite resin restorations to porcelain/ceramic laminate veneers or complete crown restorations [13] [14]. Careful planning will enable patients to attain a dentition with satisfactory esthetics and function [15].

Resin composite materials are used widely owing to their good mechanical and esthetic properties [16]. Resin composite materials show some advantages over prosthetic options, including reduced cost, protection and support for healthy tooth structure, a minimally invasive approach [17]-[19], ease of repair, and no requirement for the skills of a dental technician [16]. In the last decade, considerable improvements have been made in the properties of dental composite resins. Although some studies reported that ceramics may be superior to resin composites in terms of aesthetic and plaque accumulation [20], current new nanotechnology composites provide good clinical and laboratory results that are an alternative to prosthetic choices [13] [21] [22].

Nanocomposites are available as nanohybrid composites containing "glass fillers and nanoparticles" or as nanofill composites containing nano-sized filler particles described as "nanoclusters or nanomers" [23]. In nanocomposites, particle size is reduced and the volume is increased [24] [25]. By minimizing the filler size, nanocomposites offer excellent esthetics and polished surfaces [26]. The increased filler load provides composites increased mechanical properties such as hardness, tensile strength, compressive strength, wear resistance, and

Table 1. Classification of Amelogenesis Imperfecta according to Witkop (1988).

\begin{tabular}{l}
\hline Hypoplastic \\
\hline Hypoplastic, pitted autosomal dominant \\
Hypoplastic, local autosomal dominant \\
Hypoplastic, local autosomal recessive \\
Hypoplastic, smooth autosomal dominant \\
Hypoplastic, smooth X-linked dominant \\
Hypoplastic, rough autosomal dominant \\
Enamel agenesis, autosomal recessive \\
\hline Hypomaturation \\
\hline Hypomaturation, pigmented autosomal recessive \\
Hypomaturation, X-linked recessive \\
Snow-capped teeth, autosomal dominant \\
\hline Hypocalcified \\
\hline Autosomal dominant \\
Autosomal recessive \\
\hline Hypomaturation-hypoplastic with taurodontism \\
\hline Hypomaturation-hypoplastic with taurodontism, autosomal dominant \\
Hypoplastic-hypomaturation with taurodontism, autosomal dominant. \\
\hline
\end{tabular}


resistance to fracture [21] [24] [27]. Compared to microhybrid, microfill, or nanohybrid composite systems, nanoclusters provide a distinct reinforcing mechanism and significantly improve strength and reliability [22].

In this report, we examined the clinical effectiveness of two different nanocomposites, a nanohybrid composite (Clearfil Majesty ES-2) and a nanofilled composite (Filtek Ultimate Body), not only for laminate veneers but also for posterior class I and II restorations, in four adult patients with hypoplastic AI. In addition, we describe a rehabilitation concept based on minimal invasive therapy and conservative treatments.

\section{Case Reports}

The case report was approved by the ethics committee at the Human Ethics Committee of University of Kocaeli (KOÜ KAEK 2014/247). Four patients who were referred to the Faculty of Dentistry at the University of Kocaeli were enrolled. All patients suffered from esthetic and functional problems. The diagnosis of hypoplastic AI was based on the genetic inheritance pattern of the disorder and on clinical manifestations based on Witkop's classification (Table 1) [1] [4]. After clinical examination, all four patients were diagnosed with hypoplastic autosomal dominant type AI and pitted subtype with normal enamel thickness and hardness [1]. Radiographic examination substantiated the clinical impression and revealed mild radiolucent areas in deep enamel pits and a relatively thin opaque layer of enamel on the affected teeth. Several family members of all four patients exhibited similar dental symptoms, and three of the four patients were related (Cases 1 and 3 are sisters and Case 2 is their cousin).

The esthetic and functional rehabilitation of all four patients was performed in the Department of Restorative Dentistry of the Faculty of Dentistry at the University of Kocaeli. For composite laminate veneers, minimally invasive dental treatments were performed [19]. Only the most external porous and colored enamel layer was removed to a depth of 0.3 to $0.7 \mathrm{~mm}$ (approximately $0.5 \mathrm{~mm}$ ) and removal remained within the enamel tissue. Clearfil Universal Bond-Clearfil Majesty ES-2 (A2; nanohybrid composite; Kuraray, Japan) or Single Bond Universal-Filtek Ultimate Body (A2; nanofilled composite; 3 M ESPE, USA) were used for composite laminate veneers and posterior class I and II restorations. The composite material to be used was chosen randomly. All preparations, bonding, and composite procedures were applied according to manufacturer's instruction and were placed by same operator. Manufacturers, composition, application mode, and lot number of the materials used are presented in Table 2.

\subsection{Case 1}

Case 1 was a 19-year-old female patient (B.Y.), who suffered from esthetic and functional inadequacy of maxillary and mandibular permanent teeth, and who presented no abnormal medical history or systemic problems except for AI. Her teeth were discolored slightly yellowish/brown, and had stained, pitted, and hypoplastic enamel. In addition, the enamel appeared hard and shiny (Figure 1). A complete dental and medical examination was performed on 10 family members, and six of them were diagnosed with AI. Deciduous teeth were also affected by AI. The oral hygiene of Case 1 was good and the gingival tissue was healthy. Caries risk was assessed by examining diet, oral hygiene, and general lifestyle habits. After assessment, Case 1 was placed in a "low risk" category because of the lack of active caries at the time of evaluation [28]. Her primary concerns included excessive tooth sensitivity and esthetic problems with the upper and lower anterior and premolar teeth. Regarding restorative procedures, direct restorations were indicated in accordance with the mild severity of the affected enamel, because the patient was a young individual and was concerned with good oral hygiene and economic, esthetic, and functional outcomes. In the posterior area, resin composites were used with minimal intervention, and, in the anterior area, freehand bonded composite restorations were performed using the same approach [19] [29].

Case 1 had been treated previously with amalgam restorations on teeth 16, 17, 27, 37, 46, and 47 (Figure 1). All old amalgam restorations were replaced with composites, and a root canal treatment was performed and fiber posts were placed on teeth 26 and 36. Tooth 45 was extracted because of its position out of the mandibular arch. The upper canine teeth and lower mandibular third molar teeth were determined to be embedded in bone, and required extraction. The erupted teeth, including the anterior and posterior regions, were of normal dimension and morphology. All teeth showed normal mesial and distal contact, normal occlusion, and a normal angle Class I dental relationship. Open bite and overjet were not observed between the mandible and maxilla. There was no occlusal tooth wear or fractured enamel. The patient's vertical dimension (the vertical distance between the 
Table 2. Materials, manufacturers, composition, application mode, and lot number of the materials used.

\begin{tabular}{|c|c|c|c|}
\hline $\begin{array}{l}\text { Material and } \\
\text { Manufacturer }\end{array}$ & Composition & Application & $\begin{array}{c}\text { Lot } \\
\text { number }\end{array}$ \\
\hline $\begin{array}{l}\text { Clearfil Majesty } \\
\text { ES-2 } \\
\text { Nanohybrid composite, } \\
\text { (KURARAY Medical } \\
\text { Okuyama, Japan) }\end{array}$ & $\begin{array}{l}\text { bisphenol A diglycidylmethacrylate } \\
\text { Silanated barium glass filler } \\
\text { Pre-polymerized organic filler } \\
\text { Hydrophobic aromatic dimethacrylate } \\
\text { Hydrophobic aliphatic dimethacrylate } \\
\text { dl-Camphorquinone, Accelerators, Initiators, } \\
\text { The inorganic filler } 78 \mathrm{wt} \% \text {, } 40 \text { vol\%. } \\
0.37-1.5 \mu \mathrm{m} \text {. }\end{array}$ & $\begin{array}{l}\text { Placement of the chosen shade } \\
\text { of the paste into the cavity and } \\
\text { light-cure with a dental curing } \\
\text { unit. Considering the depth of } \\
\text { cure, incremental curing may be } \\
\text { required. }\end{array}$ & $\begin{array}{l}\text { 00020A } \\
\text { 00006A }\end{array}$ \\
\hline $\begin{array}{l}\text { Filtek Ultimate Body } \\
\text { Nanofill composite, } \\
\text { (3M ESPE } \\
\text { St Paul, MN, } \\
\text { USA) }\end{array}$ & $\begin{array}{l}\text { bis-GMA, UDMA, TEGDMA, bis-EMA, PEGDMA } \\
\text { The fillers are a combination of } \\
\text { non-agglomerated/non-aggregated } 20 \mathrm{~nm} \text { silica filler, } \\
\text { non-agglomerated/non-aggregated } 4 \text { to } 11 \mathrm{~nm} \text { zirconia } \\
\text { filler, and aggregated zirconia/silica } \\
\text { cluster filler (comprised of } 20 \mathrm{~nm} \text { silica and } 4 \text { to } 11 \mathrm{~nm} \\
\text { zirconia particles). } \\
\text { The inorganic filler } 72.5 \mathrm{wt} \%, 55.6 \text { vol\% } \\
0.6-10 \mu \mathrm{m} \text {. }\end{array}$ & $\begin{array}{l}\text { Place and light cure restoration } \\
\text { in increments for } 10 \mathrm{~s} \text { with } \\
\text { EliparTM S10 (LED lights with } \\
\text { output } 1000-2000 \mathrm{~mW} / \mathrm{cm}^{2} \text { ) }\end{array}$ & $\begin{array}{l}\text { N438989 } \\
\text { N441522 }\end{array}$ \\
\hline $\begin{array}{l}\text { Clearfil Universal Bond } \\
\text { (KURARAY Medical } \\
\text { Okuyama, Japan) }\end{array}$ & $\begin{array}{l}\text { bisphenol A diglycidylmethacrylate } \\
\text { 2-hydroxyethyl methacrylate } \\
\text { 10-Methacryloyloxydecyl dihydrogen phosphate (MDP) } \\
\text { Hydrophilic aliphatic dimethacrylate } \\
\text { Colloidal silica } \\
\text { Ethanol } \\
\text { dl-Camphorquinone, Silane coupling agent, } \\
\text { Accelerators, Initiators, Water }\end{array}$ & $\begin{array}{l}\text { Apply BOND and rub it in for } \\
10 \text { s. Dry the entire cavity wall } \\
\text { sufficiently by blowing mild air } \\
\text { for more than } 5 \mathrm{~s} \text { until bond } \\
\text { does not move. Use a vacuum } \\
\text { aspirator to prevent bond from } \\
\text { scattering. Light-cure bond with } \\
\text { a dental curing unit }\end{array}$ & 2B0005 \\
\hline $\begin{array}{c}\text { Adper Single Bond } \\
\text { Universal (3M ESPE } \\
\text { St Paul, MN, } \\
\text { USA) }\end{array}$ & $\begin{array}{l}\text { MDP phosphate monomer } \\
\text { Dimethacrylate resins } \\
\text { HEMA } \\
\text { Vitrebond copolymer } \\
\text { Filler, Ethanol, Water, Initiator } \\
\text { Silane }\end{array}$ & $\begin{array}{l}\text { Apply etchant for } 15 \mathrm{~s} \text {. Rinse } \\
\text { thoroughly with water for } 15 \mathrm{~s} \text {. } \\
\text { Rub the entire tooth structure } \\
\text { for } 20 \mathrm{~s} \text {. Direct a gentle stream } \\
\text { of air over the liquid for about } 5 \\
\mathrm{~s} \text { until it no longer moves. Light } \\
\text { cure for } 10 \mathrm{~s} \text {. }\end{array}$ & 494756 \\
\hline
\end{tabular}

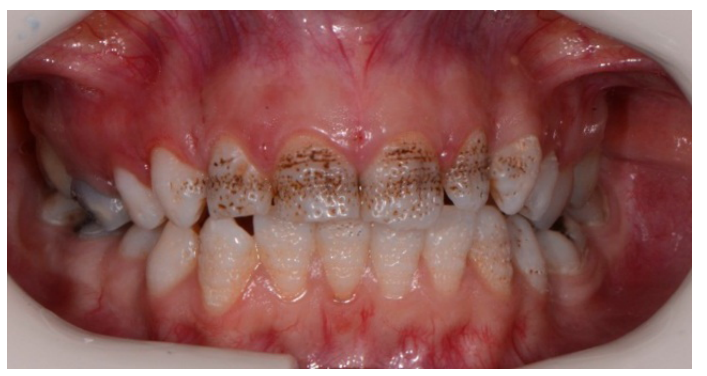

Figure 1. Clinical view at the first appointment for Case 1.

maxillary and mandibular arches or the intercuspal position at physiologic rest position) was 3 mm; therefore, no increase in the vertical dimension was needed. To verify vertical dimension, a phonetic test was performed, and the functional freeway space was evaluated [30].

\section{Clinical Procedure}

For the treatment of posterior teeth, periapical radiographs of the teeth were taken preoperatively (Figure 1). If necessary, to prevent patient discomfort during the restorative procedures, local anesthesia was administered. The teeth to be restored were cleaned with a pumice-water slurry in a rubber cup to remove the salivary pellicle and any dental plaque. Isolation was achieved with cotton rolls and saliva ejectors. Cavity preparations were limited to the removal of caries. Cylindrical and/or round diamond burs (SWS diamond burs; lot K46570) were 
used with a high-speed handpiece and constant water-cooling to access the carious lesion. Carious dentin was removed using carbide burs (Medin tungsten carbide burs; lot 11355011) and a low-speed handpiece.

For composite laminate veneers, a minimum chamfer diamond bur was used. The proximal contact area was maintained and, incisally, no preparation was necessary. Facial surfaces of the teeth were prepared by making depth-orientation grooves $(0.3 \mathrm{~mm}$ in depth) using a depth preparation diamond bur (Diatech, Coltène Whaledent; Altstätten, Switzerland). Facial reduction was continued with a tapered, rounded-end diamond bur until the color was removed from the facial surface. Facial preparation was deepened further when necessary to overcome slight discoloration. All cervical margins were placed equi-gingivally.

A total-etch strategy using 37\% phosphoric acid and bonding was applied according to the manufacturers' instruction (Table 2). After the bonding procedures, buccal/labial surfaces of upper and lower first premolars were covered with composite restorations by direct procedures. Accordingly, teeth 11, 12, 14, 41, 42, and 43 and posterior restorations of same region were constructed using Clearfil Universal Bond-Clearfil Majesty ES-2 (Figure 2). Left quadrants composite veneers at teeth 21, 22, 24, 31, 32, and 33 and posterior restorations were constructed using Single Bond Universal/Filtek Ultimate Body.

Each layer composite was cured for $20 \mathrm{~s}$ using an LED light curing unit (Elipar S10, 3 M, ESPE, St Paul MN, USA) having a minimal output of $1200 \mathrm{~mW} / \mathrm{cm}^{2}$. The light intensity output was monitored using a dental radiometer (Hilux Ledmax Light Curing Meter, Benlioğlu Dental Inc., Ankara, Turkey). Final countering and finishing of the restorations were performed using polishing points (PoGo, Dentisply), flexible discs, and finishing strips (Sof-Lex, 3 M ESPE, St Paul MN, USA). Clinical view of restorations after one year is presented in Figure 3. Fracture was observed on right maxillary first premolar at the end of one year (Figure 4).

\subsection{Case 2}

Case 2 was a 17-year-old female patient (D.Y.) with esthetic inadequacy of the anterior teeth. She had slightly yellowish/brown and stained, pitted, and hypoplastic enamel (Figure 5). The enamel appeared hard and shiny. The patient was the cousin of Case 1, and most enamel structure was similar to that of Case 1 with only low severity. There was no occlusal tooth wear, fractured enamel, or tooth sensitivity. Case 2 had small enamel and superficial dentin caries, and 2 old amalgam restorations on molar teeth 46 and 47 . The erupted teeth, including the anterior and posterior region, were of normal dimension and morphology, and all teeth showed normal mesial and distal contact, normal occlusion, and normal angle Class I dental relationships. Open bite and overjet were not observed between the mandible and maxilla. The patient's vertical dimension was normal. Oral hygiene was good, and the gingival tissue was healthy (Figure 5).

Composite veneers in the upper and lower right quadrants at teeth $11,12,13,41,42$, and 43 , and posterior restorations of same region were constructed using Clearfil Universal Bond-Clearfil Majesty ES-2 (Figure 6). Left quadrants composite veneers at teeth 21, 22, 23, 31,32, and 33, and posterior restorations were constructed using Single Bond Universal/Filtek Ultimate Body (Figure 6). Resin composites were performed in the posterior area and freehand bonded composite restorations in the anterior area were performed as in Case 1. Clinical view of restorations after one year is presented in Figure 7. Fracture was observed on mandibular right lateral incisor at the end of one year (Figure 8).

\subsection{Case 3}

Case 3 was a 17-year-old female patient (G.Y.) who presented no abnormal medical history or systemic problems except for AI. She was a sister of Case 1. A diagnosis of hypoplastic AI was made as in Case 1. She had slightly yellowish/brown and stained, pitted, and hypoplastic enamel (Figure 9). The enamel appeared hard and shiny. There was no occlusal tooth wear, fractured enamel, or tooth sensitivity. The patient's vertical dimension was normal. Oral hygiene was good and the gingival tissue was healthy. Caries risk was assessed as a "low risk". Her primary concerns included esthetic failure of the upper anterior region teeth. No orthodontic treatment was performed because the patient refused to wear brackets.

Case 3 had small enamel and superficial dentin caries on molar teeth. Composite veneers in upper right quadrants at teeth 11 and 12 and posterior restorations of same region were constructed using Clearfil Universal Bond-Clearfil Majesty ES-2 (Figure 10). Left quadrants composite veneers at teeth 21 and 22 and posterior restorations were constructed using Single Bond Universal/Filtek Ultimate Body. Conservative resin composites were performed in the posterior area and freehand bonded composite restorations in the anterior area were per- 


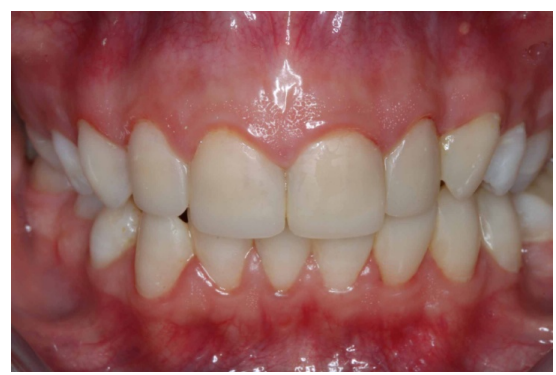

Figure 2. Intraoral view of composite laminate veneers on anterior teeth and class I, II, and III restorations on posterior teeth of Case 1 . Teeth 11, 12, 14, 41, 42, and 43 were restored with Clearfil Majesty ES-2. Teeth 21, 22, 24, 31, 32, and 33 were restored with Filtek Ultimate Body.

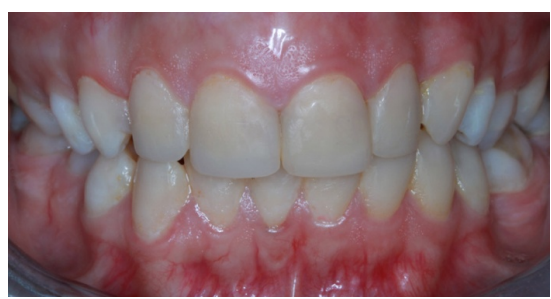

Figure 3. Clinical view of restorations after one year follow-up for Case 1.

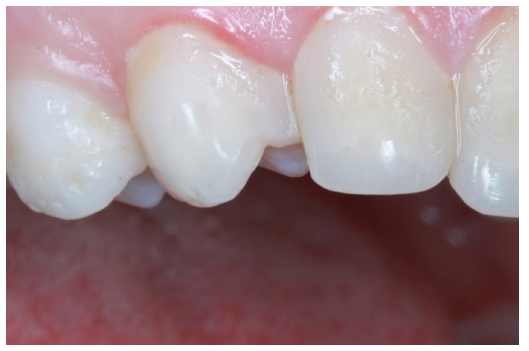

Figure 4. Fracture on right maxillary first premolar at the end of one year.

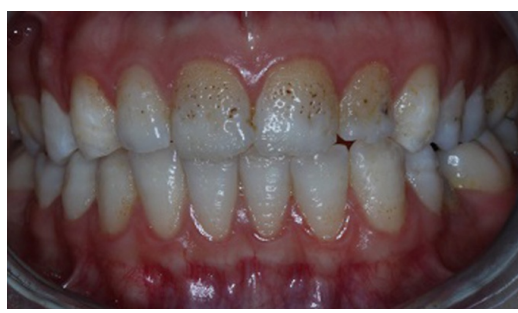

Figure 5. Clinical view at the first appointment for Case 2.

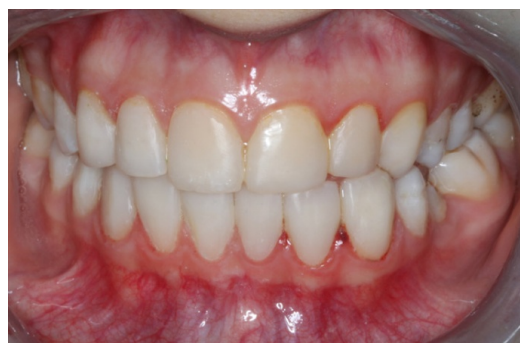

Figure 6. Intraoral view of composite laminate veneers on anterior teeth and class I restorations on posterior teeth of Case 2. Teeth 11, 12, 13, 41, 42, and 43 were restored with Clearfil Majesty ES-2. Teeth 21, 22, 23, 31, 32, and 33 were restored with Filtek ultimate body. 


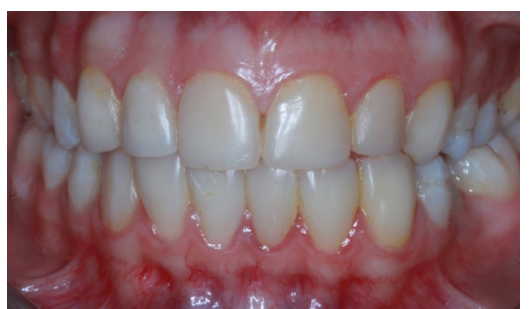

Figure 7. Clinical view of restorations after one year follow-up for Case 2.

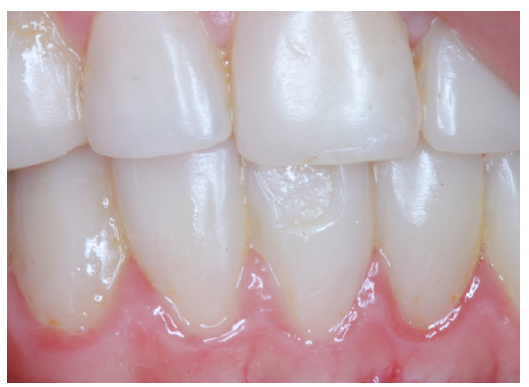

Figure 8. Fracture on mandibular right lateral incisor at the end of one year.

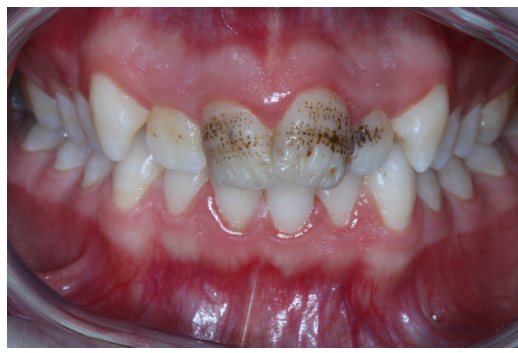

Figure 9. Clinical view at the first appointment for Case 3.

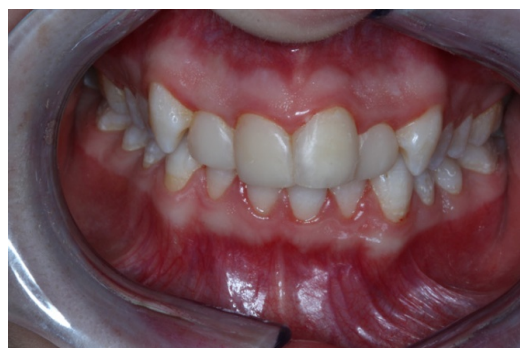

Figure 10. Intraoral view of composite laminate veneers on anterior teeth and class I restorations on posterior teeth of Case 3. Teeth 11 and 12 were restored with Clearfil Majesty ES-2. Teeth 21 and 22 were restored with Filtek ultimate body.

formed as in Case 1. Clinical view of restorations after one year is presented in Figure 11.

\subsection{Case 4}

Case 4 was a healthy 30-year-old female (H.F.) who presented AI and required complex management. Her main initial concern was extensively carious posterior teeth, a sensitivity to hot and cold, and dissatisfaction with the appearance of the anterior teeth, especially those with pitted hypoplastic enamel (Figure 12). According to anamnesis, her twin sister, father, grandfather, and cousins had similar tooth structure similar to hypoplastic AI. She had no abnormal medical history or systemic problems. There was minimal occlusal tooth wear, without exposed dentin. Premature loss of vertical dimension, open-bite, overjet, and diastema were not observed. Case 4 had poor oral hygiene with moderate to severe plaque accumulation, which caused generalized gingivitis, ex- 
tensive caries, and several unsatisfactory restorations. She wanted to improve the appearance of her anterior teeth, especially those that were brown and stained with pitted, hypoplastic enamel.

Clinical examination revealed the presence of hypoplasia in the form of grooves, lines, pigmented pits, and areas with thin enamel. There were diffuse opacities, teeth with shape and color alterations, and areas with fractured enamel. The posterior teeth presented open cavities and fractured amalgam restorations. She had previously been treated with amalgam restorations on teeth $15,35,45$, and 47 , which were replaced with composite. Teeth 16, 17, and 37 had root canal treatment. Tooth 18 was determined to require extraction, and teeth 25, 26, $27,28,38$, and 48 were restored with composite. Tooth 31 was already extracted approximately one year previous, and tooth 41 was determined to require extraction because of insufficient bone support. Prosthetic treatments were planned for teeth 33 and 43.

Upper composite laminate veneers (between teeth 14 - 24) and posterior restorations were placed in upper right quadrants using Clearfil Universal Bond-Clearfil Majesty ES-2 (Figure 13). Left quadrants were treated using Single Bond Universal-Filtek Ultimate Body (Figure 13). Resin composites were performed in the posterior area and freehand bonded composite restorations in the anterior area were performed as in Case 1. Clinical view of restorations after one year is presented in Figure 14.

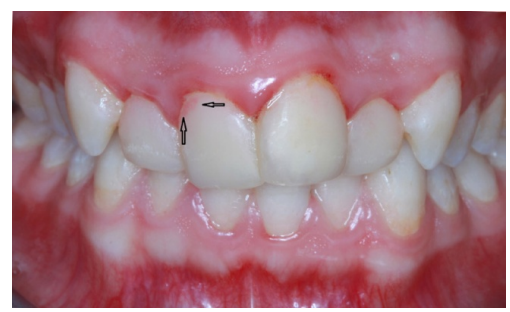

Figure 11. Clinical view of restorations after one year follow-up for Case 3.

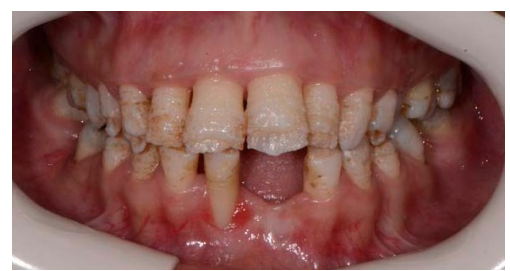

Figure 12. Clinical view at the first appointment for Case 4.

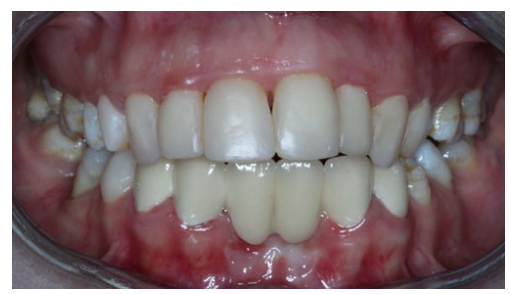

Figure 13. Intraoral view of composite laminate veneers on anterior teeth and direct composite restorations on posterior teeth of Case 4. Teeth 11, 12, 13, and 14 were restored with Clearfil Majesty ES-2. Teeth 21, 22, 23, and 24 were restored with Filtek ultimate body.

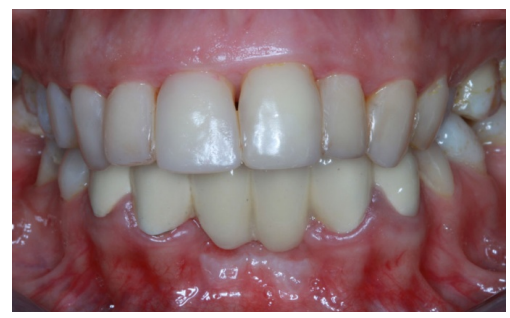

Figure 14. Clinical view of restorations after one year follow-up for Case 4. 


\section{Discussion}

In this report, the diagnosis of hypoplastic AI was made based on the Witkop's classification [1]. Although this is the most widely used classification, the clinical heterogeneity of AI makes an accurate diagnosis difficult because of the lack of objective radiographic and clinical criteria [6]. Classification is usually based on the enamel defect and the mode of inheritance pattern and phenotype in the family [14]. In the present report, we diagnosed AI via the inheritance pattern, the hard and shiny appearance of the enamel, and the specific pitting structure of enamel. In addition, the region of pits showed yellowish brown colors, and the patients have impacted teeth.

An important aspect of this report is that all treatments were based exclusively on adhesive technology, and followed the principle of minimal invasiveness. Nanohybrid (Clearfil Majesty ES-2) and nanofilled (Filtek Ultimate Body) composites were used in the anterior composite laminate veneers and in the posterior restorations. The results using nanocomposite materials at the anterior and posterior regions in the AI patients were successful at the immediate term in this case report. Consistent with our results, Sabatini et al. [13] reported that, with proper isolation and careful handling, direct-bonded resin composite restorations provide an excellent conservative treatment for the protection of teeth weakened because of AI.

Studies have shown that posterior restorations require composites with greater mechanical properties, while anterior restorations require composites with superior esthetics. Karabela et al. [31] reported that a resin composite that meets all the requirements of both posterior and anterior restorations has not emerged. However, according to Moszner and Klapdohr [24], and Turssi et al. [32], dental nanocomposites combine the good mechanical strength of the hybrid composites and the superior polishing property of the microfilled composites.

Only a few laboratory or clinical studies have investigated the bonding effectiveness of dentin bonding agents to AI affected teeth because of the limited number of extracted teeth or the limited number of patients with AI. Faria-e-Silva et al. [33] reported that higher bond strengths are obtained to normal tooth tissues than to hypomineralized teeth affected by AI. William et al. [34] reported that the microshear bond strength of resin composite bonded to hypomineralized enamel was significantly lower than that to normal enamel for Single Bond and Clearfil SE Bond. Both laboratory studies used hypomineralized AI specimens, whereas, all four patients enrolled in this study were diagnosed as hypoplastic AI. In the hypomineralized AI, calcification of the organic matrix is deficient. However, in hypoplastic AI, the enamel is correctly mineralized, but there is a deficiency in the quantity of enamel [13]. Thus, the results of the studies may not correlate with our results. Yaman et al. [35] reported that Clearfil SE Bond exhibited 29.24 MPa in normal enamel and 18.21 MPa microtensile bond strength in hypoplastic enamel. In addition, they reported that Adper Single Bond 2 showed 31.59 MPa in normal enamel and 19.63 MPa in hypoplastic enamel [35]. In the present study, we removed approximately $0.5 \mathrm{~mm}$ of the external layer (AI affected layer) of the anterior teeth to reach layers of healthy tissue that could ensure good adhesion. Furthermore, the bond strength values may depend on the severity of the defect. The four cases enrolled in the current report showed only mild severity of hypoplastic AI. The mild severity was also confirmed with intra and extra oral radiographic examination to determine differences in enamel and dentin hard tissue contrast.

Two different Universal Bonding agents were used in treatments that are produced by the same manufacturers as the composites. Universal adhesives represent recent generation of adhesives in the market. They were designed under the all-in-one concept of existing one-step self-etch adhesives, but are also offered to clinicians to use in different etch and rinse modes. These simplified self-etch universal adhesives are ultra-mild systems that do not disturb the inorganic component of enamel. However, etching enamel with phosphoric acid is often recommended [36]. Studies have reported that the preliminary etching of ground enamel prior to application of bonding significantly increases the bond strength of the adhesives [36] [37]. Muñoz et al. [37] reported that the microtensile bond strength ( $\mu \mathrm{TBS}$ ) of Scotchbond Universal and All Bond Universal were 35.1 and 39.3 MPa, respectively, in etch and rinse mode, but 32.4 and 13.4 MPa, respectively, in self etch mode. Therefore, to provide better bonding in the enamel tissue, we used both universal bonding agents in a total etch strategy. Nevertheless, marginal leakage on central incisor was determined after one year for Case 3.

\section{Conclusion}

In these cases, we used minimal invasive operative care in all restorations of four patients affected by AI. The principles of treatments and the selection of materials were planned for minimal intervention. The final restorations exhibited not only good esthetics, but also a return to optimal function, as well as providing complete cov- 
erage of all affected areas. These restorations not only addressed the patients' hypersensitivity issue, but the patients' concerns of esthetic appearance. Careful consideration of a patient's expectations and conditions is critical for successful treatment and to achieve patient satisfaction.

\section{Conflict of Interest}

The authors declare that there is no conflict of interests regarding the publication of this paper.

\section{References}

[1] Witkop Jr., C.R. (1988) Amelogenesis, Dentinogenesis Imperfecta and Dentin Dysplasia Revisited: Problems in Classification. Journal of Oral Pathology, 17, 547-553. http://dx.doi.org/10.1111/j.1600-0714.1988.tb01332.x

[2] McDonald, R.E. and Avery, D.R. (2001) Dentistry for Child and Adolescent [in Portuguese]. Guanabara Koogan, Rio de Janeiro, 608.

[3] Ravassipour, D.B., Powell, C.M., Phillips, C.L., Hart, P.S., Hart, T.C., Boyd, C. and Wright, J.T. (2005) Variation in Dental and Skeletal Open Bite Malocclusion in Humans with Amelogenesis Imperfecta. Archieves of Oral Biology, 50, 611-623. http://dx.doi.org/10.1016/j.archoralbio.2004.12.003

[4] Encinas, R.P., Garcia-Espona, I. and Mondelo, J.M.N.R. (2001) Amelogenesis Imperfecta: Diagnosis and Resolution of a Case with Hypoplasia and Hypocalcification of Enamel, Dental Agenesis, and Skeletal Open Bite. Quintessence International, 32, 183-189.

[5] Peters, E., Cohen, M. and Altini, M. (1992) Rough Hypoplastic Amelogenesis Imperfecta with Follicular Hyperplasia. Oral Surgery Oral Medicine Oral Pathology, 74, 87-92. http://dx.doi.org/10.1016/0030-4220(92)90220-K

[6] Collins, M.A., Mauriello, S.M., Tyndall, D.A. and Wright, J.T. (1999) Dental Anomalies Associated with Amelogenesis Imperfecta, A Radiographic Assessment. Oral Surgery Oral Medicine Oral Pathology, 88, 358-364. http://dx.doi.org/10.1016/S1079-2104(99)70043-0

[7] Robinson, C., Brookes, S.J., Shore, R.C. and Kirkham, J. (1998) The Developing Enamel Matrix: Nature and Function. European Journal of Oral Science, 106, 282-291. http://dx.doi.org/10.1111/j.1600-0722.1998.tb02188.x

[8] Barclay, C.W. and Walmsley, A.D. (1998) Amelogenesis Imperfecta. In: Barclay, C.W. and Walmsley, A.D., Eds., Fixed and Removable Prosthodontics, Churchill Livingstone, Edinburg, 29-30.

[9] Seow, W.K. (1993) Clinical Diagnosis and Management Strategies of Amelogenesis Imperfect Variants. Pediatric Dentistry, 15, 384-393.

[10] Lau, E.C., Slavkin, H.C. and Snead, M.L. (1990) Analysis of Human Enamel Genes Insights into Genetic Disorders of Enamel. Cleft Palate Journal, 27, 121-130. http://dx.doi.org/10.1597/1545-1569(1990)027<0121:AOHEGI>2.3.CO;2

[11] Uchida, T., Tanabe, Y., Fukae, M. and Shimizu, M. (1991) Immunocytochemical and Immunochemical Detection of a $32 \mathrm{kDa}$ Nonamelogenin and Related Proteins in Porcine Tooth Germs. Archives of Histology \& Cytology, 54, 527-538. http://dx.doi.org/10.1679/aohc.54.527

[12] Oliveira, I.K., Fonseca, J.de F., do Amaral, F.L., Pecorari, V.G., Basting, R.T. and França, F.M. (2011) Diagnosis and Esthetic Functional Rehabilitation of a Patient with Amelogenesis Imperfecta. Quintessence International, 42, 463-469.

[13] Sabatini, C. and Guzman-Armstrong, S. (2009) A Conservative Treatment for Amelogenesis Imperfect with direct Resin Composite Restorations: A Case Report. Journal of Esthetic and Restorative Dentistry, 21, 161-170. http://dx.doi.org/10.1111/j.1708-8240.2009.00258.x

[14] Yamaguti, P.M., Acevedo, A.C. and de Paula, L.M. (2006) Rehabilitation of an Adolescent with Autosomal Dominant Amelogenesis Imperfect: Case Report. Operative Dentistry, 31, 266-272. http://dx.doi.org/10.2341/05-1

[15] Robinson, F.G. and Haubenreich, J.E. (2006) Oral Rehabilitation of a Young Adult with Hypoplastic Amelogenesis Imperfecta: A Clinical Report. Journal of Prosthetic Dentistry, 95, 10-13. http://dx.doi.org/10.1016/j.prosdent.2005.10.013

[16] Ardu, S., Duc, O., Krejci, I. and Perroud, R. (2013) Amelogenesis Imperfecta: A Conservative and Progressive Adhesive Treatment Concept. Operative Dentistry, 38, 235-241. http://dx.doi.org/10.2341/11-437-S

[17] Dietschi, D. (2001) Layering Concepts in Anterior Composite Restorations. Journal of Adhesive Dentistry, 3, 71-80.

[18] Quinonez, R., Hoover, R. and Wright, J.T. (2000) Transitional Anterior Esthetic Restorations for Patients with Enamel Defects. Pediatric Dentistry, 22, 65-67.

[19] Peters, M.C. and McLean, M.E. (2001) Minimally Invasive Operative Care. I. Minimal Intervention and Concepts for Minimally Invasive Cavity Preparations. Journal of Adhesive Dentistry, 3, 7-16. 
[20] Auschill, T.M., Arweiler, N.B., Brecx, M., Reich, E., Sculean, A. and Netuschil, L. (2002) The Effect of Dental Restorative Materials on Dental Biofilm. European Journal of Oral Science, 110, 48-53. http://dx.doi.org/10.1046/j.0909-8836.2001.101160.x

[21] Chen, M.H., Chen, C.R., Hsu, S.H., Sun, S.P. and Su, W.F. (2006) Low Shrinkage Light Curable Nanocomposite for Dental Restorative Material. Dental Materials, 22, 138-145. http://dx.doi.org/10.1016/j.dental.2005.02.012

[22] Curtis, A.R., Palin, W.M., Fleming, G.J.P., Shortall, A.C.C. and Marquis, P.M. (2009) The Mechanical Properties of Nanofilled Resin-Based Composites: The Impact of Dry and Wet Cyclic Pre-Loading on Bi-Axial Flexure Strength. Dental Materials, 25, 188-197. http://dx.doi.org/10.1016/j.dental.2008.06.003

[23] Mitra, S.B., Wu, D. and Holmes, B.N. (2003) An Application of Nanotechnology in Advanced Dental Materials. Journal of American Dental Association, 134, 1382-1390. http://dx.doi.org/10.14219/jada.archive.2003.0054

[24] Moszner, N. and Klapdohr, S. (2004) Nanotechnology for Dental Composites. International Journal of Nanotechnology, 1, 130-156. http://dx.doi.org/10.1504/IJNT.2004.003723

[25] Han, J.M., Zhang, H., Choe, H.S., Lin, H., Zheng, G. and Hong, G. (2014) Abrasive Wear and Surface Roughness of Contemporary Dental Composite Resin. Dental Materials Journal, 5, 725-732. http://dx.doi.org/10.4012/dmj.2013-339

[26] Marghalani, H.Y. (2010) Effect of Filler Particles on Surface Roughness of Experimental Composite Series. Journal of Applied Oral Science, 18, 59-67. http://dx.doi.org/10.1590/S1678-77572010000100011

[27] Sideridou, I.D., Karabela, M.M. and Vouvoudi, E.C. (2011) Physical Properties of Current Dental Nanohybrid and Nanofill Light-Cured Resin Composites. Dental Materials, 27, 598-607. http://dx.doi.org/10.1016/j.dental.2011.02.015

[28] Featherstone, J.D.B., White, J.M., Hoover, C.I., Rapozo-Hilo, M., Weintraub, J.A., Wilson, R.S., Zhan, L. and Gansky, S.A. (2012) A Randomized Clinical Trial of Anticaries Therapies Targeted According to Risk Assessment (Caries Management by Risk Assessment). Caries Research, 46, 118-129. http://dx.doi.org/10.1159/000337241

[29] Ritter, A.V. (2005) Direct Resin-Based Composites: Current Recommendations for Optimal Clinical Results. Compendium of Continuing Education in Dentistry, 26, 481-490.

[30] Tamaki, T. (1923) Dentaduras Completas. 4th Edition, Sarvier, São Paulo.

[31] Karabela, M.M. and Sideridou, I.D. (2011) Synthesis and Study of Properties of Dental Resin Composites with Different Nanosilica Particles Size. Dental Materials, 27, 825-835. http://dx.doi.org/10.1016/j.dental.2011.04.008

[32] Turssi, C.P., Saad, J.R., Duarte, S.L. and Rodrigues, A.L. (2000) Composite Surfaces after Finishing and Polishing Techniques. American Journal of Dentistry, 13, 136-138.

[33] Faria-e-Silva, A.L., De Moraes, R.R., Menezes, Mde. S., Capanema, R.R., De Moura, A.S. and Martelli Jr., H. (2011) Hardness and Microshear Bond Strength to Enamel and Dentin of Permanent Teeth with Hypocalcified Amelogenesis Imperfecta. International Journal of Paediatric Dentistry, 21, 314-320. http://dx.doi.org/10.1111/j.1365-263X.2011.01129.x

[34] William, V., Burrow, M.F., Palamara, J.E.A. and Messer, L.B. (2006) Microshear Bond Strength of Resin Composite to Teeth Affected by Molar Hypomineralization Using 2 Adhesive Systems. Pediatric Dentistry, 28, 233-241.

[35] Yaman, B.C., Ozer, F., Cabukusta, C.S., Eren, M.M., Koray, F. and Blatz, M.B. (2014) Microtensile Bond Strength to Enamel Affected by Hypoplastic Amelogenesis Imperfecta. Journal of Adhesive Dentistry, 16, 7-14.

[36] Hanabusa, M., Mine, A., Kuboki, T., Momoi, Y., Van Ende, A., Van Meerbeek, B. and De Munck, J. (2012) Bonding Effectiveness of a New "Multi-Mode" Adhesive to Enamel and Dentine. Journal of Dentistry, 40, 475-484. http://dx.doi.org/10.1016/j.jdent.2012.02.012

[37] Muñoz, M.A., Luque, I., Hass, V., Reis, A., Loguercio, A.D. and Bombarda, N.H. (2013) Immediate Bonding Properties of Universal Adhesives to Dentine. Journal of Dentistry, 41, 404-411. http://dx.doi.org/10.1016/j.jdent.2013.03.001 